\title{
Optimization of Electrical and Morphological Properties of MCrAlY thin films deposited by DC magnetron sputtering using Taguchi method
}

\author{
Vinaya B C ${ }^{\dagger *}$, K M Narayanappa ${ }^{\dagger}$ and B S Praveen Kumar ${ }^{\#}$ \\ ${ }^{\dagger}$ Department of Mechanical Engineering, Dr Ambedkar Institute of Technology, Bengaluru, Karnataka, India \\ \# Department of Mechanical Engineering, Presidency University, Bengaluru, Karnataka, India
}

Received 06 Sept 2018, Accepted 10 Nov 2018, Available online 12 Nov, Vol.8, No.6 (Nov/Dec 2018)

\begin{abstract}
The objective of the research work was to optimize and standardize sputtering parameters based on physical parameters and electrical properties of the coatings. The experimental and statistical investigation was conducted for optimizing the sputtering parameters. The sputtering parameters were selected as sputtering power, working gas pressure, substrate temperature and deposition time. For coating of MCrAlY thin film on a borofloat glass substrate, the electrolytic MCrAlY target was used based on a design of experiment layout. The thin film coatings were characterized for film thickness and surface roughness. The optimum conditions for maximum thickness and minimum surface roughness are sputtering power $(17.57 \mathrm{~W})$, working gas pressure $\left(5 \times 10^{-3} \mathrm{mbar}\right)$, substrate temperature $\left(100^{\circ} \mathrm{C}\right)$ and deposition time $(32 \mathrm{~min})$. The ANOVA results for film thickness showed the contribution of deposition time (93.92) followed by working pressure (3.26\%), substrate temperature (2.052\%) and power (0.646 $\%$ ).
\end{abstract}

Keywords: Thin Film coating, Sputtering, Design of Experiments, ANOVA.

\section{Introduction}

Thin film materials have the advantages of posing same characteristics or sometimes even better characteristics than the bulk materials. Its low material consumption and minimal machining make it preferable for use in the complex areas where bulk material cannot give suitable output result. The scope and market of thin film is dominating in sensor application, MCrAlY has a low electrical resistivity, relatively high temperature stability, good electromigration resistance. Amorphous films containing Si, C, and $\mathrm{H}$ (denoted as $\mathrm{Si}: \mathrm{C}: \mathrm{H}$ ) is of interest in photovoltaic and thin film transistor applications (J.Onuki et al, 1992; Jiang et al, 1997; L.H. Qian et al,2004). Such films are also of growing interest in MCrAlY interconnect applications such as low dielectric constant materials (Copper et al, 1997; S. P. Muraka et al, 2000; U. Haas et al, 2002).The study of MCrAlY thin films has been commonly centered on the physical and electrical properties of the MCrAlY films deposited with numerous deposition techniques, such as electrodeposition, chemical vapor deposition (CVD), pulsed laser deposition and magnetrons sputtering (Ali

*Corrresponding author's ORCID ID: 0000-0002-6874-5960 DOI: https://doi.org/10.14741/ijcet/v.8.6.6
Gelali et al, 2002). The magnetron sputtering is a simple and low-cost method of obtaining thin films of metal, alloys, nitrides, carbides or oxides. Magnetron sputtering has lot of advantages like: high deposition rate, high purity and homogeneity of obtained films, high adhesion and high precision of the control of obtained films. Sputtering has been the preferred method for manufacturing integrated cirMCrAlY it's, microsystems or semiconductors, interconnects and multilayers sensors (J. Onuki et al, 1992; W.Y. Chou et al, 2005; Ali Gelali et al, 2012). Many researches initiatives have been reported over the last decade on developing of thin films for various uses. In the present research work, the focus was to systematically examine the physical properties and electrical properties of copper thin films deposited with dc magnetron sputtering technique as per the Taguchi L16 orthogonal array technique. The objective of the research paper was to optimization of sputtering parameters affecting the film thickness and surface roughness by Taguchi's orthogonal array.

\section{Experimental Studies}

Two types of materials are used in sputtering process. First one is the material on which sputter deposition is being carried out, known as the substrate material and 
second one is the material being used as a source material in the sputtering process, is known as target material. In this report, borofloat glass is used as a substrate material and electrolytic copper is used as the target metal. Commercially available electrolytic MCrAlY (99.99\%) pure was used as the target material in the sputtering process. The diameter of target material used was 3 inch with a thickness of $3 \mathrm{~mm}$.

The borofloat glass substrates of size $25 \times 35 \mathrm{~mm}$ were cut by using a diamond glass cutter. It was rinsed in soap water and cleaned ultrasonically in acetone and isopropanol, each for 10 minutes and blown dry in nitrogen. Any impurities on the glass substrate would cause the formation of pores on the film and also may lead to poor adhesion of the film. AFM characterization was conducted on a glass substrate to check there surface roughness. Surface roughness of the glass substrates were found to be $1 \mathrm{~nm}$, which was quite good for the experiment. Better surface roughness results in homogeneous films. After verifying the roughness, the glass substrates were placed in vacuum chamber for sputtering process.

For sputtering process in the experiment, SPUTTER 100 machine was used for deposition of thin MCrAlY film Sputter 100 is configured for upward sputtering by Argon (Ar) and oxygen $\left(\mathrm{O}_{2}\right)$ gases. The major component in it is vacuum chamber, vacuum system cabinet and control system cabinet. The glass substrates were fixed in a rotatable substrate holder by using Kapton tape in the correct position. Then the chamber was taken to rough vacuum by using rotary pump and then to high vacuum by using turbo pumps. The distance between the target and substrate was kept constant for all the experiments conducted as per parameters mentioned in Table 1, which was obtained by Design of Experiments tool.

Table 1,2 The run sheet for DC magnetron sputtering system as per the input parameters from design of experiments

\begin{tabular}{|c|c|c|c|}
\hline \multirow{4}{*}{$\begin{array}{c}\text { Run } \\
\text { No }\end{array}$} & \multirow{2}{*}{\multicolumn{3}{|c|}{$\begin{array}{c}\text { Run sheet for DC Magnetron sputtering } \\
\text { system } \\
\text { Target: Electrolytic copper }\end{array}$}} \\
\hline & & & \\
\hline & \multicolumn{2}{|c|}{ VaMCrAlYum (mbar) } & \multirow[b]{2}{*}{$\underset{\left({ }^{\circ} \mathrm{C}\right)}{\text { Temp }}$} \\
\hline & $\begin{array}{c}\text { PNG } \\
\left(\mathrm{x} 10^{-3}\right)\end{array}$ & $\begin{array}{c}\text { CM-1 } \\
\left(\mathrm{x} 10^{-5}\right)\end{array}$ & \\
\hline 1 & 3 & 5.0 & 25 \\
\hline 2 & 3 & 6.0 & 25 \\
\hline 3 & 3 & 5.5 & 25 \\
\hline 4 & 3 & 6.5 & 25 \\
\hline 5 & 3 & 6.5 & 50 \\
\hline 6 & 3 & 5.5 & 50 \\
\hline 7 & 3 & 5.0 & 50 \\
\hline 8 & 3 & 6.0 & 50 \\
\hline 9 & 3 & 5.5 & 75 \\
\hline 10 & 3 & 6.5 & 75 \\
\hline 11 & 3 & 6.0 & 75 \\
\hline 12 & 3 & 5.0 & 75 \\
\hline 13 & 3 & 6.5 & 100 \\
\hline 14 & 3 & 5.0 & 100 \\
\hline 15 & 3 & 5.5 & 100 \\
\hline 16 & 3 & 6.0 & 100 \\
\hline
\end{tabular}

\begin{tabular}{|c|c|c|c|c|c|}
\hline \multirow{4}{*}{$\begin{array}{c}\text { Run } \\
\text { No }\end{array}$} & \multicolumn{5}{|c|}{$\begin{array}{l}\text { Run sheet for DC Magnetron sputtering } \\
\text { system }\end{array}$} \\
\hline & \multicolumn{5}{|c|}{ Substrate: Borofloat glass } \\
\hline & \multicolumn{5}{|c|}{ MAG-1 Target: } \\
\hline & 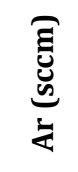 & 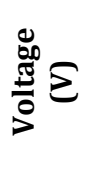 & 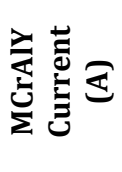 & $\begin{array}{l}\sum_{0} \\
\vdots \\
\vdots \\
0 \\
0\end{array}$ & 宅 导 \\
\hline 1 & 130 & 675 & 0.02 & 15 & 8 \\
\hline 2 & 145 & 610 & 0.04 & 25 & 16 \\
\hline 3 & 155 & 750 & 0.0 & 30 & 24 \\
\hline 4 & 138 & 554 & 0.03 & 20 & 32 \\
\hline 5 & 160 & 570 & 0.04 & 25 & 8 \\
\hline 6 & 137 & 540 & 0.02 & 15 & 16 \\
\hline 7 & 138 & 608 & 0.03 & 20 & 24 \\
\hline 8 & 146 & 630 & 0.04 & 30 & 32 \\
\hline 9 & 140 & 670 & 0.04 & 30 & 8 \\
\hline 10 & 165 & 527 & 0.03 & 20 & 16 \\
\hline 11 & 145 & 504 & 0.03 & 15 & 24 \\
\hline 12 & 138 & 661 & 0.03 & 25 & 32 \\
\hline 13 & 158 & 640 & 0.03 & 20 & 8 \\
\hline 14 & 128 & 730 & 0.04 & 30 & 16 \\
\hline 15 & 143 & 627 & 0.04 & 25 & 24 \\
\hline 16 & 158 & 502 & 0.03 & 15 & 32 \\
\hline
\end{tabular}

Optimization of the deposited thin films is the main task in order to get the device quality films. This has to be carried out on the basis of detailed structural, morphological, compositional and electrical properties of the films obtained at different growth conditions. The relevant theories and apparatuses of the principal characterization techniques used throughout the present work elaborated. The experimental techniques used include Dektak surface profilometer, atomic force microscopy (AFM), X-ray diffraction, scanning electron microscopy and two point probe technique. In the following sections the techniques used for the film characterizations are discussed briefly.

\section{Results and discussion}

Thin films deposited by using dc magnetron sputtering were checked on dektak surface profilometer. The thickness of the film changes as the input parameter of deposition changes. The entire sample shows the linear increase in the thickness as its input parameter increases. The thickness tends to increase more as the time of deposition and working power increases. The thickness of thin film was lowest of $208 \mathrm{~nm}$ for the input parameter as power-20 W, working pressure$6.0 \times 10^{-3}$ mbar, substrate temperature $100^{\circ} \mathrm{C}$, and deposition time as 8 minutes. And highest film thickness of $802 \mathrm{~nm}$ was found at the input parameters of power-30 W, working pressure $6.5 \times 10^{-3} \mathrm{mbar}$, substrate temperature $25^{\circ} \mathrm{C}$ and deposition time of 24 $\min$. 
Table 3 Variation of output response with respect to input parameters

\begin{tabular}{|c|c|c|c|c|c|}
\hline \multicolumn{5}{|c|}{ Input parameters } & $\begin{array}{c}\text { Subs } \\
\text { Output } \\
\text { response }\end{array}$ \\
\hline $\begin{array}{c}\text { Sl } \\
\text { N } \\
\text { o }\end{array}$ & $\begin{array}{c}\text { Power } \\
\text { (w) }\end{array}$ & $\begin{array}{c}\text { Pressure } \\
\text { (x10-3 } \\
\text { mbar) }\end{array}$ & $\begin{array}{c}\text { Tem } \\
\text { p } \\
\left(\mathbf{0}^{\mathbf{C}}\right)\end{array}$ & $\begin{array}{c}\text { Dep. } \\
\text { Time } \\
\text { (min) }\end{array}$ & $\begin{array}{c}\text { Film } \\
\text { thickness } \\
\text { (nm) }\end{array}$ \\
\hline 1 & 15 & 5.0 & 25 & 8 & 253 \\
\hline 2 & 15 & 5.5 & 50 & 16 & 360 \\
\hline 3 & 15 & 6.0 & 75 & 24 & 545 \\
\hline 4 & 15 & 6.5 & 100 & 32 & 766 \\
\hline 5 & 20 & 5.0 & 50 & 24 & 486 \\
\hline 6 & 20 & 5.5 & 25 & 32 & 734 \\
\hline 7 & 20 & 6.0 & 100 & 8 & 208 \\
\hline 8 & 20 & 6.5 & 75 & 16 & 441 \\
\hline 9 & 25 & 5.0 & 75 & 32 & 713 \\
\hline 10 & 25 & 5.5 & 100 & 24 & 572 \\
\hline 11 & 25 & 6.0 & 25 & 16 & 453 \\
\hline 12 & 25 & 6.5 & 50 & 8 & 280 \\
\hline 13 & 30 & 5.0 & 100 & 16 & 365 \\
\hline 14 & 30 & 5.5 & 75 & 8 & 228 \\
\hline 15 & 30 & 6.0 & 50 & 32 & 718 \\
\hline 16 & 30 & 6.5 & 25 & 24 & 694 \\
\hline & & & & & \\
\hline
\end{tabular}

Fig.1 shows the effect of power, working pressure, substrate temperature and deposition time on thickness of MCrAlY coatings. Only two parameters have greater influence on coating thickness such as working pressure and deposition time as shown. The other two parameters i.e, sputtering power and substrate temperature influence less significantly. The coating thickness increases with increasing power, but decreased with increased substrate temperature. The optimum values for larger response are $30 \mathrm{~W}$ sputtering power, $6 \times 10^{-3}$ mbar gas pressure, $25^{\circ} \mathrm{C}$ substrate temperature and 32 min of deposition time.

\section{Analysis of variance for thin film thickness}

Table 4 ANOVA table for thin film thickness

\begin{tabular}{|c|c|c|c|c|c|c|}
\hline Factor & DOF & $\begin{array}{c}\text { Sum } \\
\text { of } \\
\text { squares }\end{array}$ & $\begin{array}{c}\text { Mean } \\
\text { square }\end{array}$ & $\mathrm{F}_{\text {cal }}$ & $\mathrm{P}$ & $\begin{array}{c}\text { contri } \\
(\%)\end{array}$ \\
\hline $\begin{array}{c}\text { Dep } \\
\text { time(m) }\end{array}$ & 3 & 538657 & 17955 & 805 & 0.0 & 93.92 \\
\hline $\begin{array}{c}\text { Subs } \\
\text { temp }\left({ }^{\circ} \mathrm{C}\right)\end{array}$ & 3 & 11769 & 3923 & 17.55 & 0.02 & 2.052 \\
\hline $\begin{array}{c}\text { press } \\
10^{-3} \\
\text { mbar }\end{array}$ & 3 & 18700 & 6233 & 27.95 & 0.01 & 3.26 \\
\hline Power & 3 & 3705 & 1235 & 5.53 & 0.09 & 0.646 \\
\hline Error & 3 & 670 & 223 & & & 0.116 \\
\hline Total & 15 & 573502 & & & & 100 \\
\hline
\end{tabular}

The ANOVA for thin film thickness are tabulated in Table 3. The $\mathrm{R}^{2}$ value of developed empirical model for film thickness is $99.884 \%$. The high $\mathrm{R}^{2}$ value indicates that better the model fits our data. $\mathrm{F}$ ratio is computed as the ratio of factor mean square to the error mean square. Larger $\mathrm{F}$ values indicate that the variation of the process parameters makes a big change on film thickness. Here $0.0000 \mathrm{P}$ value of deposition time factor is significant.

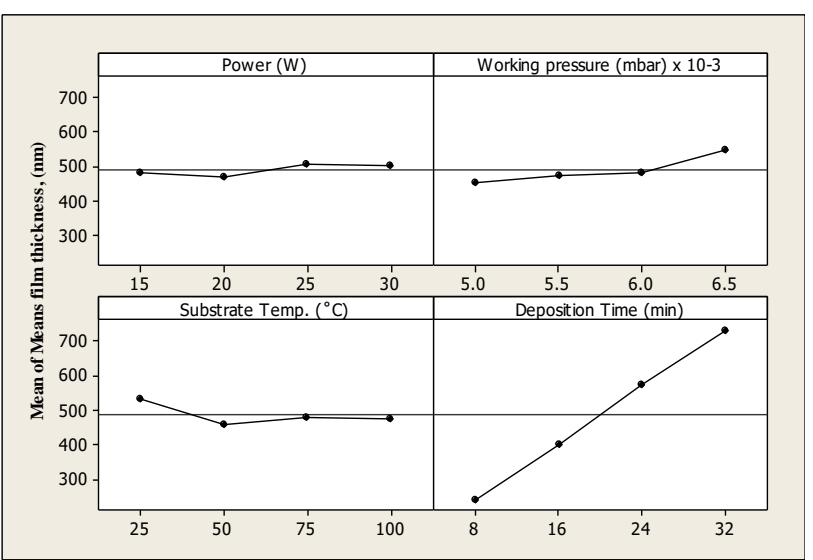

Fig. 1 Effect of input parameters on film thickness of copper thin film on glass substrate using DC magnetron sputtering

\section{Conclusions}

Experimental studies of thin films deposited by using L16 orthogonal array on dc magnetron sputtering were undertaken. The four factors in L16 factorial experiment were designed considering power, working pressure, substrate temperature and deposition time as input parameters with film thickness response. From the ANOVA results of film thickness, $F_{\text {calwas }}$ highest since for the deposition time then followed by working pressure, substrate temperature and power. Hence deposition time (93.92\%) was found to be significant factor, followed by working pressure (3.26\%), substrate temperature (2.052\%) and sputtering power $(0.646 \%)$ for film thickness. The confirmatory test for film thickness was found to be $676 \mathrm{~nm}$ film thickness which is in agreement with the optimization result of $704 \mathrm{~nm}$ film thickness for the set range of film thickness and surface roughness based on RSM.

\section{References}

J. Onuki, Y. Koubuchi, M. Suwa, D. Gardner, H. Suzuki, E. Minowa,(1992)IEEE Trans. Electron Devices vol-39,no-2 pp-1322-1349.

Jiang H, Klemmer T.J, Barnard J.A, Doyle W.D, Payzant E.A. Epitaxial (1997) growth of MCrAlY (111) films on Si (110) by magnetron sputtering: orientation and twin growth. Thin Solid Filmsvol-315, pp-13-16.

L.H. Qian, Q.H. Lu, W.J. Kong, K. Lu, Scr(2004). Material. SolidState Material Advance Technology, vol-50 pp-1407-17.

Copper in Electrical Contacts(1997), CDA Publication vol-23.

S. P. Muraka., I. V. Verner and R. J. Gutmann(2000), Copper Fundamental Mechanisms for Microelectronic Applications, Wileycanada publishers.

U. Haas, A. Haase, H. Maresch, B. Stadlober, G. Leising(2002), $4^{\text {th }}$ International Conference on Polymers and Adhesives in Microelectronics and Photonics,pp-12-15, Portland, USA. 
Ali Gelali, AzinAhmadpourian, Reza Bavadi, M. R. Hantehzadeh and Arman. Ahmadpourian(2002) Characterization of Microroughness Parameters in Titanium Nitride Thin Films Grown by DC Magnetron Sputtering, J. of Fusion Energy, vol-31, no-6, pp- 586-590.

J. Onuki, Y. Koubuchi, M. Suwa, D. Gardner, H. Suzuki, E. Minowa(1992),IEEE Trans. Electron Devicesvol-39, no-4, pp-1322-1334
W.Y. Chou, B.Y. Tsui, C.W. Kuo, T.K. Kang(2005) Optimizationof Back Side Cleaning Process to Eliminate Copper Contamination Semiconductor devices, materials, and processing, Journals of Electrochemical Society, vol-152, no-2, pp-131-137.

Ali Gelali, AzinAhmadpourian, Reza Bavadi, M. R. Hantehzadeh and Arman. Ahmadpourian (2012),Characterization of Microroughness Parameters in Titanium Nitride Thin Films Grown by DC Magnetron Sputtering, Journal of Fusion Energy,vol-31, no-6, pp-586590. 